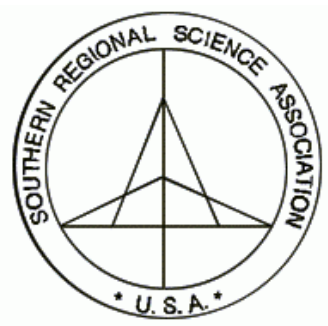

The Review of Regional Studies

Oklahoma State University

\title{
Advances and Declines in the Rural Working Poor: Complementing Traditional Econometric Results with Case Analysis
}

\author{
Scott Loveridge \\ 202 Agricultural Hall, Department of Agricultural, Food, and Resource Economics, \\ Michigan State University, East Lansing MI 48824, e-mail: loverid2@anr.msu.edu \\ Linda Lobao \\ The Ohio State University \\ Pamela Thomas \\ The Ohio State University \\ W. Trevor Brooks \\ South Dakota State University \\ Janet L. Bokemeier \\ Michigan State University \\ Richard Goe \\ Kansas State University \\ Nicole A. Bradshaw \\ Michigan State University \\ Donna J. Hess \\ South Dakota State University \\ Michael W. McCurry \\ South Dakota State University
}

\begin{abstract}
We employ a multi-method approach to more fully explore determinants of greater than expected rural county-level increases and decreases in the proportion of working poor in four states. An econometric model by Anderson, Goe, and Weng (2007) using 1990 and 2000 Census data in the North Central region of the U.S. supplies the error terms to identify our outlier counties. We show that counties performing better than expected may be more self-reliant than counties performing worse than expected (Michigan), that regional attributes contribute greatly to overall performance (Ohio), that the structure of local employment patterns also influences outcomes (Missouri), while devolution of federal government and long-term commuting patterns may also affect outcomes (South Dakota). Future efforts should attempt to replicate these research strategies and may serve to inform the direction of best practice in federal data collection efforts.
\end{abstract}

Keywords: Poverty; Transition; Outlier

JEL classification: C80; I32; O18 


\section{INTRODUCTION}

Over the past 20 years, the field of econometrics has advanced considerably. Personal computers and off-the-shelf software have made sophisticated tests readily available. A broad array of scholars from economics, geography, mathematics, sociology, and of course, statistics have contributed a huge menu of estimation procedures and nonparametric tests. Most notable among these new procedures from the perspective of the regional scientist is the availability of tests of spatial association (Anselin 1988, LeSage 1999).

The low expense and increased sophistication of econometrics should have ushered in a golden age of exploring the determinants of changes in regions' socio-economic status. While contributions to the regional science literature routinely avail themselves of these techniques, to say that they have led to watershed conclusions about appropriate policies for sustained economic growth or knowledge about how to create more equitably distributed growth among regions would be an overstatement. Why haven't the new techniques and increased ease of analysis helped more? Our position is that the issue is not related to the available econometric techniques, but that we are measuring social and economic trends rather than the underlying causes of those trends. Although federal data sets have notable strengths for providing generalizable and longitudinal data, in some sense they have perhaps limited the scope of studies of the determinants of regional change. It is much easier to develop a hypothesis and search for a federal data set that might shed light upon the question than it is to conduct a survey. For example, in attempting to explain migration away from the heartland to the southwest, scholars have used federal weather data and established a positive relationship between sunshine and growth (McGranahan 1999; McKean et al. 2005; Reeder and Brown 2005; Rappaport 2007). The researchers might instead have asked people why they moved, but the answer to that question was not part of a federal data set. Had they asked, researchers might have been told people were moving for jobs. It rains in gray places, which means the region can sustain rainfed agriculture, which is good for annual crops. The business of planting and harvesting rainfed crops has become highly mechanized, releasing people from the workforce. These same cold, gray places were good places to set up factories in early years of manufacturing because cooling systems had not yet been perfected and because the people knew how to run machines due to the nature of the local agriculture. Concentration of manufacturing led to conditions for unionization, which in turn lead to incentives to automate, releasing people from the workforce. So we see movement of people from cold, gray places to sunny places or places with cool, less humid summers where a greater proportion of the workforce is in labor-intensive service sectors. While some may indeed be moving for the sunshine or cool summers, the picture is more complex than the bald econometrics would imply.

We note that standard econometric practice has come to accept as sufficiently rigorous models that explain 20 to 30 percent of the variance in cross-sectional studies of people or places. So most of the variability remains unexplained, and our parameter estimates are therefore susceptible to omitted variable bias. 
Changes in federal socio-economic data sets have been marginal. Some data series have been dropped. Others have been modified slightly to keep up with changing times. The U.S. Bureau of the Census has created mechanisms to make uncensored analysis of the data slightly more available through a network of centers and is in the process of replacing the old decennial long form with annual (or, for rural areas, three year) estimates from the American Community Survey. But in large measure, today's data are the same as the data available to researchers before the advent of the personal computer. The time has come to assess the benefits of expanding the types of information contained in national data sets to keep pace with advances in econometrics and theories of community and regional development.

Another issue with the current state of econometric analysis is that our equations tend to explain developments in those areas that approach the average. More intellectually interesting are the places that do not conform to established patterns of development. If a place is declining or advancing more rapidly than other places with similar sociodemographic, geographic, and industry characteristics, we ought to know why. Current data and modeling procedures fall short in explaining the trajectory of exceptional places. This may be due to misspecification, or due to such immeasurables such as quality of leadership, or seldom-measured items such as policy choices. Outliers, therefore, are an excellent benchmark that is underutilized in policy assessment. ${ }^{1}$

We argue in this article that many more insights can be gained by complementing econometric analysis with coordinated, in-depth, multi-state exploration of factors associated with exceptional changes in local conditions. We first provide a summary of the Anderson, Goe, and Weng (2007) model that produces outlier counties for study. We do not critique this model; rather we use the model outputs to identify rural outlier counties that seem to be advancing or declining faster than advanced modeling procedures would predict. We then use state-level networks, data, and intelligence to shed light on characteristics of these outlier counties in four states, using a different approach in each state. We focus on counties that represent outliers in the change in the proportion of the working poor in rural areas. It is important to develop a deeper understanding of these changes as the economy globalizes, potentially creating a permanent underclass in certain regions of the country. Rural areas may be particularly susceptible to this due to their geographic isolation and resulting undiversified, low technology, commodity-based, high labor input local economies. Our results have implications for future research and for rethinking the types of information that could complement existing federal data sets. We conclude with recommendations for further research and data collection activities.

\section{ANDERSON, GOE, AND WENG (2007) MODEL}

We begin where a model of the North Central region of the United States developed by Anderson, Goe, and Weng (2007) ends. They used 1990 and 2000 county-level Census data to estimate determinants of the growth in the proportion of working poor in

\footnotetext{
${ }^{1}$ The authors thank an anonymous reviewer for this comment.
} 
counties in the 12 states of the North Central region of the U.S. Their basic model is summarized in equation 1.

$$
\text { 2000pr }=\mathrm{f}(1990 \mathrm{pr}, \text { rural, } \text { ic, } \mathrm{dc})
$$

Where: $2000 \mathrm{pr}=$ Year 2000 percent working poor 1990pr $=$ Year 1990 percent working poor

ic = Industrial composition, measured as percent employed in ag/mining, construction, service, and government

$\mathrm{dc}=$ Labor force composition, measured as percent female labor, nonwhite labor, young labor, female headed households, elderly headed households, and college labor.

The specification also included a spatial lag term.

Outliers from the model are presented in Figure 1, with lightly shaded counties indicating that the model underpredicts the decrease in the rate of working poor and darkly shaded counties indicating the model underpredicts the increase in the rate of working poor. Casual observation leads to the conclusion that even with a spatial lag term, there appears to be clustering of counties that do not fit the model well, indicating that there may be systematic areas of difference that state-of-the-art modeling has missed. We explore potential missing variables in the case studies that follow. Our case study counties are chosen based on available supplemental data sets and contacts. The case study counties are circled in Figure $1 .^{2}$

\section{OUTLIERS IN MICHIGAN'S UPPER PENINSULA ${ }^{3}$}

In this section, we show how a survey of local attitudes can complement understanding of the results of models using only federal data. The Anderson, Goe, and Weng (2007) model identified several rural Michigan counties as outliers. Most of these fall within Michigan's Upper Peninsula (UP), so we focus our attention on that region. The UP is larger than some states in area and is home to roughly 317 thousand people (Census 2000), including several Native American tribes. Per capita income in the UP in 2000 was about $\$ 17,000$, which would make the region forty-eighth among the states if it were a separate state. The region's economic base is primarily mining, forestry, and tourism. We supplement the Anderson, Goe, and Weng findings with an independent survey of household attitudes towards economic development in the UP.

\footnotetext{
${ }^{2}$ The authors thank C. Weng for supplying this graphic.

${ }^{3}$ Data presented in the Michigan section were collected with support from CSREES National Research Initiative Competitive Grant No. 2003-35401-13781.
} 


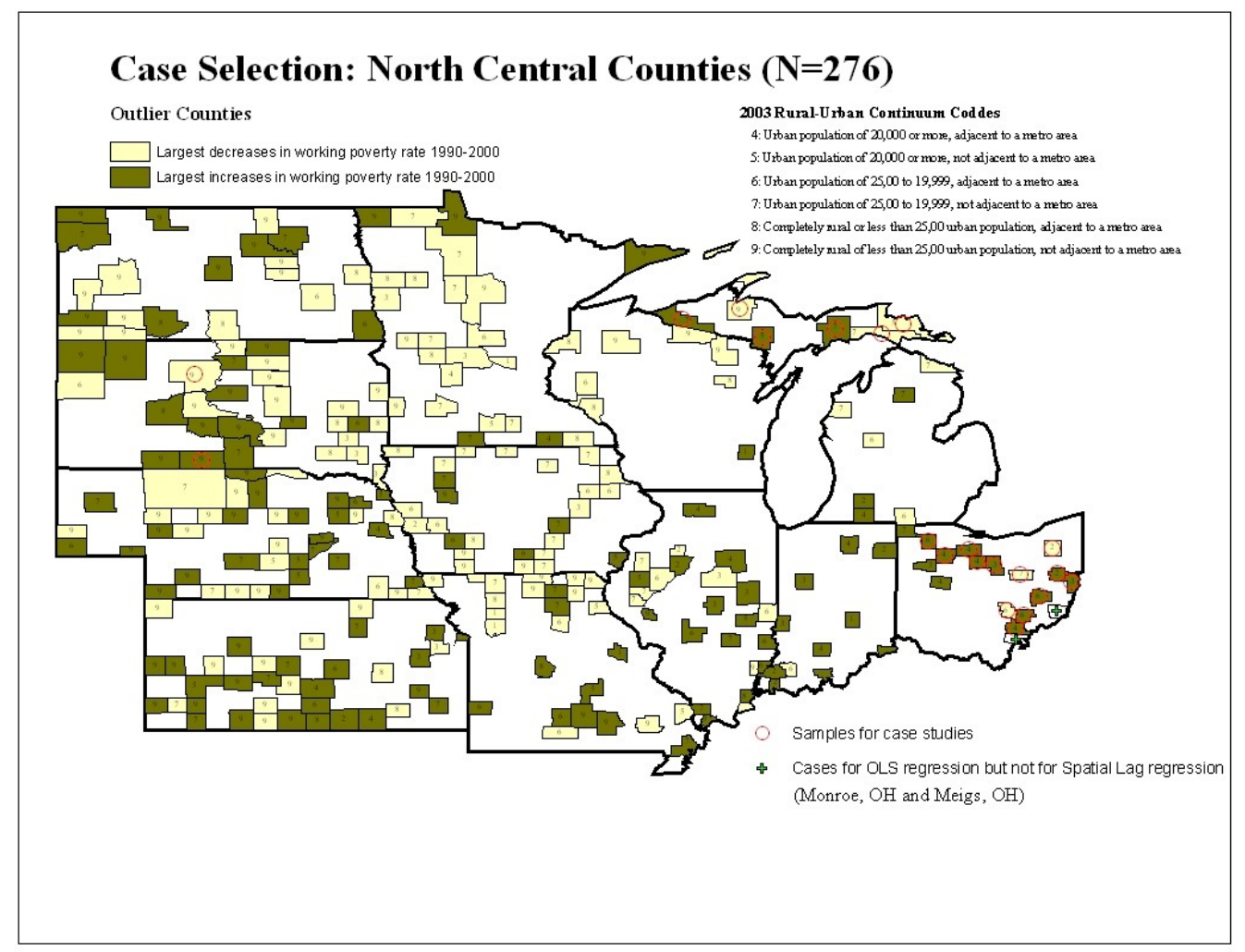

FIGURE 1. Outliers from the Anderson, Goe, and Weng (2007) Model (Case study counties circled.)

Our basic data ${ }^{4}$ were collected in 2004 via a telephone survey of randomly selected residents. A total of 1,270 interviews were completed, including those drawn from the general population and an oversample of Native Americans. A total of 10,131 phone numbers were used (mining company workers, a general UP random digit dial segment, and the directory listed numbers in census tracts with high proportions of Native Americans screened only for Native Americans). Only persons 18 to 64 years of age were eligible. Within households containing at least one eligible adult, the respondent was selected randomly using the Troldahl and Carter (1964) technique. Using the outcome dispositions categories of the American Association of Public Opinion Researchers' Standard

\footnotetext{
${ }^{4}$ The data were collected under contract by the Office for Survey Research of the Institute for Public Policy and Social Research (IPPSR) at Michigan State University. While IPPSR accepts responsibility for the quality of the data, the interpretations and conclusions presented are solely those of the authors. This paragraph and the next are based on the methods report presented to the investigators by IPPSR.
} 
Definitions, the overall response rate for the survey was 43.5 percent. ${ }^{5}$ Population probability measures were used to determine weights. The survey asked respondents to report their zip codes, allowing us to match to zip code aggregate data from the 2000 U.S. Census and determine their county of residence. ${ }^{6}$

The survey included a scenario involving community benefits (jobs). Focus groups conducted in the UP in Fall of 2003 provided information in developing the scenario and in framing additional survey questions. Respondents could choose:

- 16 jobs in the community in five years,

- 10 jobs now,

- $\quad$ to never get new jobs;

- indifference between 10 jobs now and 16 jobs in five years, or

- that they were undecided.

The tradeoff between 10 jobs now or 16 jobs in five years provided a rate of return of 10 percent, or well above prevailing interest rates. The number of jobs in the scenario was chosen to be small enough so that the overall impact on housing and other consumer prices in the community would be marginal and so that the respondents would not worry about a large influx of newcomers changing local culture. The type of company (computer software) was selected as likely to be viewed as noncompetitive with existing firms and nonpolluting, so therefore unlikely to generate negative externalities. Nonetheless, 18 percent of respondents stated they would "never" want the company to move to their area. Follow-up questions asked whether the respondents would object to a $\$ 50,000$ subsidy to the firm and whether they would object to a $\$ 50,000$ subsidy to entice an existing firm to remain in the area. For a more complete discussion of overall survey results, see Loveridge, Bokemeier, and Kakela (2007).

The Anderson, Goe, and Weng (2007) econometric analysis found that in the UP, Baraga, Chippewa, and Mackinac counties are reducing the proportion of working poor faster than predicted by their multistate model. We classify these counties as "advancing." Similarly, Gogebic, Dickinson, and Schoolcraft are increasing the proportion of working poor faster than predicted. We classify these counties as "declining." The remaining counties fit the model reasonably well, and we classify them as "fit."

\footnotetext{
${ }^{5}$ The refusal rate was 21.6 percent (REF2), the cooperation rate among eligible households was 66.9 percent (COOP4), and the contact rate was 93.7 percent (CON3). The response rate was slightly higher for the overall sample than for the Native American targeted segment. A total of approximately 54,500 phone calls was made to complete the survey. The average number of calls required to reach a final outcome disposition for the UP random digit dial segment of the sample was 5.79, while it was 4.3 for the Native American targeted segment of the sample.

${ }^{6}$ County of residence could not be determined for 27 cases due to nonresponse or non-UP zip code recorded, bringing the total number of cases to 1,243 .
} 
The county classifications are cross-tabulated with the survey responses about preferences for the timing of the software company arrival and attitudes about subsidies in Tables 1, 2, and 3. Table 1 shows that respondents living in advancing counties seem to be much more likely to choose to "never" get the new computer software company than fit or declining counties. Reinforcing this is Table 2, which shows that respondents from advancing counties are more likely to disapprove of a subsidy to get the firm. Finally, Table 3 shows that respondents in advancing counties are very similar to declining counties in their approval of subsidies to existing firms, indicating that they are not necessarily more opposed to subsidies.

\section{TABLE 1}

Outlier Status and Preference for Timing of Arrival of New Computer Software Company (counts in parentheses)

\begin{tabular}{|c|c|c|c|c|c|}
\hline & \multicolumn{3}{|c|}{ Outlier Status of Respondent's County } & \multirow{2}{*}{ Total } \\
\hline & & Advancing & Fit & Declining & \\
\hline \multirow{4}{*}{$\begin{array}{l}\text { Want } \\
\text { company } \\
\text { to move } \\
\text { when? }\end{array}$} & Today with 10 jobs & $45.4 \%(99)$ & $56.8 \%(462)$ & $45.8 \%(97)$ & $52.9 \% \quad(658)$ \\
\hline & In 5 Years with 16 jobs & $22.5 \%(49)$ & $21.0 \%(171)$ & $41.0 \%(87)$ & $24.7 \% \quad(307)$ \\
\hline & Never & $31.2 \%(68)$ & $17.8 \%(145)$ & $6.1 \%(13)$ & $18.2 \% \quad(226)$ \\
\hline & No preference & $.9 \% \quad(2)$ & $4.3 \% \quad(35)$ & $7.1 \%(15)$ & $4.2 \% \quad(52)$ \\
\hline Total & & $100 \%(218)$ & $100 \%(813)$ & $100 \%(212)$ & $100 \%(1,243)$ \\
\hline
\end{tabular}

TABLE 2

Outlier Status and Approval of \$50,000 Subsidy for New Company (counts in parentheses)

\begin{tabular}{|c|c|c|c|c|c|}
\hline & & \multicolumn{3}{|c|}{ Outlier Status of Respondent's County } & \multirow{2}{*}{ Total } \\
\hline & & Advancing & Fit & Declining & \\
\hline \multirow{2}{*}{$\begin{array}{l}\text { Want company } \\
\text { to get subsidy to } \\
\text { come }\end{array}$} & Approve & $32.4 \%(70)$ & $47.8 \%(366)$ & $66.8 \%(131)$ & $48.1 \%(567)$ \\
\hline & Disapprove & $67.6 \%(146)$ & $52.2 \%(400)$ & $33.2 \%(65)$ & $51.9 \%(611)$ \\
\hline Total & & 100\% (216) & $100 \% \quad(766)$ & 100\% (196) & $100 \%(1,178)$ \\
\hline
\end{tabular}


TABLE 3

Outlier Status and Approval of \$50,000 Subsidy to Existing Company (counts in parentheses)

\begin{tabular}{|c|c|c|c|c|c|}
\hline & & \multicolumn{3}{|c|}{ Outlier Status of Respondent's County } & \multirow{2}{*}{ Total } \\
\hline & & Advancing & Fit & Declining & \\
\hline \multirow{2}{*}{$\begin{array}{l}\text { Want } \\
\text { company to } \\
\text { get subsidy } \\
\text { to stay }\end{array}$} & Approve & $75.1 \%(163)$ & $68.7 \%(546)$ & $76.5 \%(153)$ & $71.1 \%(862)$ \\
\hline & Disapprove & $24.9 \% \quad(54)$ & $31.3 \%(249)$ & $23.5 \% \quad(47)$ & $28.9 \%(350)$ \\
\hline Total & & $100 \%(217)$ & $100 \% \quad(795)$ & $100 \% \quad(200)$ & $100 \%(1,212)$ \\
\hline
\end{tabular}

Indications for Table 3 are reinforced with exploration of respondents' household income. A Chi-square test of respondent household income category ${ }^{7}$ returned asymptotic two-sided significance of 0.107 , indicating respondents do not vary significantly across our three outlier categories in terms of income category. This is important to consider because strong variability in respondent income across the outlier categories might lead to differing attitudes towards economic development.

Our Michigan analysis shows that advancing and declining counties are different in their attitudes towards economic development strategies. The advancing counties appear to be more oriented towards self-reliance and growth from within as opposed to seeking economic stimuli from external sources. These community attitudes may be playing a role in their ability, under similar structural circumstances as nearby counties, to pull ahead of predicted performance in reducing the number of working poor. On the other hand, declining counties may be more oriented towards external growth due to desperation, which in turn exacerbates their situation due to reliance on short-term, quick-fix options for local growth.

\section{CHARACTERISTICS OF NEW MADRID COUNTY, A MISSOURI OUTLIER}

In this section, we show how additional public data sets and key informant interviews can complement models based on Census data. New Madrid County, Missouri, was among those rural counties with the highest increases in the percentage of working poor within the North Central region between 1990 and 2000. In 2000, the percent working poor was 15.1 percent, compared to 13.6 percent in 1990 (U.S. Census of Population and Housing 2003). Further, as indicated by the findings from the Anderson, Goe, and Weng (2007) model, New Madrid County had a much higher-than-expected increase given its location, employment composition, and demographic characteristics compared to other rural counties in the region. New Madrid County is located on Interstate 55 in the lower

\footnotetext{
${ }^{7} \$ 29,000$ or less, $\$ 30,000$ to $\$ 59,000, \$ 60,000$ or more, or don’t know/refused.
} 
southeast region of Missouri in the so-called "boot-heel" of the state. In 2000, the county had a population of 19,760 persons; 8,140 were employed in the civilian labor force (U.S. Census of Population and Housing 2003).

The county seat is the city of New Madrid, which had a population of 3,359 persons in 2000 (U.S. Census of Population and Housing, 2003). New Madrid is located in the central part of the county, directly abutting the Mississippi River as it winds its way south from St. Louis toward Memphis, Tennessee. The city of Sikeston, with a population of 17,015 in 2000, straddles the northern boundary of the county (U.S. Census of Population and Housing, 2003). Part of this city is located in New Madrid County, while the remainder is located in Scott County to the north. Sikeston and New Madrid represent the largest and most significant communities in the county. The county population is dominated by Caucasians, although there is also a substantial representation of African-Americans. In 2000, 83.1 percent of the county population was Caucasian, compared to 75.1 percent in the nation as a whole. Further, 15.7 percent of the population was African-American, compared to 12.2 percent in the nation.

In addition to experiencing one of the largest increases in working poor during 19902000, incomes in the county were substantially lower compared to the nation. In 1999, the average household income, at $\$ 35,027$, was $\$ 21,617$ lower than that of the nation; the median household income, at \$26,826, was \$15,171 dollars less; and 22.1 percent of the county population lived in poverty in 2000 compared to 12.4 percent for the nation (U.S. Census of Population and Housing 2003). In effect, almost one out of every four persons in New Madrid County lived in poverty in 2000.

The economic base of New Madrid County is dominated by agriculture and manufacturing. The county's agricultural sector is dominated by large family farms. In 2002, approximately 42.3 percent of the farms in the county were more than 1,000 acres in size, with the average farm size being 1,085 acres. Approximately 58.8 percent of the farms have over $\$ 100,000$ in sales; the average net farm income is $\$ 94,477$. The primary commodities produced include corn, rice, and soybeans (U.S. Census of Agriculture, 2002). Based on a composite of data sources, the percentage of employment in the county accounted for by agriculture ranges between 8 to 17 percent (U.S. Census of Population and Housing 2003, Census of Agriculture 2002), versus 1.5 percent nationally (U.S. Census of Population and Housing 2003). Out of this component of the employed labor force, almost two-thirds are hired farm workers. During 2002, the majority of hired farm workers were employed less than 150 days during the year (i.e., were temporary) (U.S. Census of Agriculture 2002). This suggests that the agricultural sector contributes to the working poor population by providing a substantial number of temporary jobs.

In 2000, the manufacturing sector accounted for 25.2 percent of total employment versus 14.1 percent nationally (U.S. Census of Population and Housing 2003). While there are a number of locally-based firms, manufacturing is dominated by branch establishments of nonlocal firms that are multinational or national in scope. The largest employer in the county is Canadian-based Noranda Aluminum, which operates a large 
aluminum smelting facility. Other important manufacturing firms with establishments in the county include Good Humor-Breyers, Cargill Fertilizer, Koch Industries, Helena Chemical, and Riceland Foods.

Local employment in the manufacturing sector is characterized by instability and fluctuations. Periodic layoffs occur at Noranda Aluminum and other firms. A locallybased firm that formerly manufactured remote telephone stations, Kontek Industries was negatively affected by the bursting of the Internet bubble in 2000 and terminated a large number of workers. Ironically, the firm recovered by changing its primary products following the attacks on the World Trade Center. Today it again employs a large number of workers in the production of vehicle and blast barriers for security purposes (Southeast Missourian 2004). The local manufacturing sector has also been affected by globalization as a number of factories have closed and shifted production to Mexico and other offshore locations. During the 1998-2003 period, there was an estimated net decline of 499 manufacturing jobs (Community Economic Toolbox 2006). An even more severe decline occurred during the 2001-2004 period with an estimated net decline of 1,736 manufacturing jobs in the county (Missouri Economic Research and Information Center 2006).

It is reasonable to believe that a key reason that multinational and national manufacturing firms located branch establishments in New Madrid County is because local wages are sufficiently low. In fact, the city of New Madrid directly advertises on its Web site that a new employer will be able to attract employees from a pool of 9,400 underemployed workers in New Madrid County and the surrounding five county area (City of New Madrid 2006). Thus, the manufacturing sector likely contributes to the working poor population through the provision of low-wage employment. Also, since the manufacturing sector is predominantly comprised of establishments of nonlocal firms, it is likely that needed inputs are not sourced locally, but purchased from external, lower-cost vendors. Therefore, local multiplier effects are not extensive, which indirectly contributes to lower wages in other sectors of the county economy.

The local communities have not been passive in attempting to stimulate economic development in the post-2000 period. Through the efforts of Representative Jo Ann Emerson (R-Missouri), they have been successful in attracting dollars through federal economic development programs. A grant was obtained to finance the restoration of the river front in the city of New Madrid. A federally-funded center for job training has been established. Finally, a rural enterprise zone has been created (Missouri Department of Economic Development 2006). On top of these policy efforts, employment within the local manufacturing sector has started to rebound as a net increase of 712 manufacturing jobs occurred during 2004-2005 (Missouri Economic Research and Information Center 2006). It remains to be seen whether and how these initiatives and trends influence the size of the working poor population in the first decade of the twenty-first century. While we can only speculate about the reasons for New Madrid's focus on low-wage manufacturing jobs as an economic development strategy, some of the reasons summarized by Loveridge (1996) might apply. These include a) simple adherence to existing traditions, b) high political visibility for successful projects due to numbers of employees, c) low 
organizational capacity to carry out alternative economic development strategies, d) lack of patience for longer term economic development approaches, or e) a feeling that recruitment of low-wage jobs can be successful anywhere if public incentives are large enough. Other authors (Molotch 1976; Zekeri 2000) hypothesize that the elite may structure economic policies to enhance their own, as opposed to community-wide, benefits. Owners of real estate may apply pressure for policies that allow a return on their invested capital, resulting in pursuit of low-wage companies to occupy vacant land or empty facilities. As Reese and Rosenfeld (2002) point out, the propensity of a place to pursue the interests of a few elite is a function of cultural attributes. Measurement of a community's leadership culture is an understudied area.

\section{THE OHIO OUTLIERS}

The case of Ohio adds another set of potential explanations regarding outliers. In this section we show how comparisons within and across categories and taking situational elements into consideration can increase understanding of poverty outcomes. Compared to most other states in the North Central region, Ohio is relatively urbanized, has a smaller farm population, and shares a distinct history as an energy and industrial heartland of the northern manufacturing belt. In Ohio, 15 out of the 88 counties were outliers, 11 had high increases in the proportion of working poor, and four had the highest decreases. To understand these patterns, we provide two analyses, the first comparing the high working poverty counties with non-outlier counties, and the second comparing within the outlier counties. These two sets of comparisons should, respectively, identify potential distinguishing factors within the state as a whole related to the growth of the working poor while providing contrasts among the outliers.

In both cases, we draw conceptually from past work by Lobao (2004) that argues for attention to four conceptual factors that affect the distribution of poverty and other forms of inequality across space. The first is local economic structure of industries, firms, and jobs, which reflects the quantity and quality of employment needed to pull workers out of poverty. Second are local institutional arrangements particularly between government, local employers, and civic society/citizens. A more activist local government that protects citizens' livelihoods while fostering growth may reduce poverty. Third, spatial site and situation factors can affect poverty. Places have different internal, location-related site characteristics (population density, roads, and other ecological features and infrastructure), and each has a different situation or position in the regional economy. Finally, places are affected by their history of the factors above, reflecting the broader process of path dependency in regional processes.

\subsection{Counties Where the Working Poor Increased Compared to Other (Non-Outlier) Counties}

To understand the factors distinguishing counties where the number of working poor grew, we used an array of variables from secondary data, including variables that were not directly incorporated in the Anderson, Goe, and Weng (2007) regression analysis. 
These variables are mainly from the 1990 and 2000 Censuses of Population and from U.S. counties. One goal here is to assess whether these counties were distinctly different at the start of the Anderson, Goe, and Weng analysis, with 1990 as the benchmark year. Findings below are based on t-tests comparing increased working poor outlier counties with the remaining 73 non-outlier counties. These findings are statistically significant unless noted otherwise, based on significance levels of 0.1 since the sample size is small.

First, in terms of socioeconomic well-being, family poverty rates in outlier counties were only slighter higher in 1990, but appear to be a great deal higher in 2000 relative to other counties. Median family income was lower in both 1990 and 2000. These descriptive statistics show that outlier counties did not keep up with others despite the 1990s boom years. In terms of economic structure, there were few significant differences in employment structure in 1990, as might be expected since these were controlled in the Anderson, Goe, and Weng regression models. However, employment in mining was significantly higher in 1990 in these counties relative to non-outlier counties.

Some major differences were found with regard to institutional arrangements, however, reflecting the different role of local government. The proportion of general and total revenues from state government was higher than in other counties, while local government expenditures per capita were lower (based on 1997 data from Census of Governments with the source U.S. counties). Outlier counties also tend to have smaller county governments, and they are less likely to have a property tax. This suggests a less active local governmental system and more dependence on federal- and state-level policies and programs. It also suggests that it in the analysis of outliers, it is important to give greater attention to the role of government since this is not well-captured in the Anderson Goe, and Weng (2007) regression model. Other aspects of institutional arrangements reflecting the bargaining power of labor, such as educational attainments and the dependent population-reflecting social safety net needs-were not significantly different. Last, outlier counties also had lower population density, even though in other attributes of rurality they differed little from Ohio overall.

To appraise factors related to spatial site, situation in the global economy, and past history, we needed to go beyond secondary data. Mapping these counties provides evidence of the importance of these factors. Outlier counties where poverty decreased less than expected were situated largely in regions that had a distinct history in the regional economy. There are three sets of regions where these counties are located.

1) The northwestern rural manufacturing belt. For example, outliers Henry, Seneca, and Hancock are located near Toledo, while Crawford and Richland are located in the Mansfield MSA. These counties still are less population dense than other parts of the state. There are longer commuting distances to jobs, and the MSAs in/near which they are located tend to be poorer and have experienced long-term de-industrialization. 
2) The old Ohio River Valley manufacturing belt. For example, outlier counties Jefferson, Carroll, and Guernsey are located here, a region where steel, glass, mining, and other indigenous industries have long been in decline.

3) Appalachia, or the lower Ohio River Valley. Outlier counties Athens, Meigs, and Morgan are located in this historically relatively impoverished region. ${ }^{8}$

These three regions distinctly contrast with growth areas in Ohio, such as the DaytonSpringfield area that tends to be characterized by higher quality manufacturing in higher technology sectors, and the Columbus metro area, home of the state capital and the state's major university.

In summary, characteristics of the local state and distinct past history of the regions in which these counties are located seem to differentiate outlier counties from others. Both factors are important, as highlighted when we move to the second analysis below.

\subsection{Comparison among Outlier Counties Only}

Here we compare outlier counties where the proportion of working poor decreased with outlier counties where the proportion of working poor increased. For this comparison, we cannot examine relationships statistically since there are only four counties in the reduced working poor group of counties. Using secondary data and mapping the counties, reduced working poor poverty may have occurred for two possible reasons.

1) Increased urban spread effects related to regional location within Ohio. For example, based on mapping the four counties where working poverty decreased: Morrow borders Delaware, the highest growth county in central Ohio, part of the Columbus MSA; Perry borders Fairfield, part of the Columbus MSA; Portage is part of the Cleveland-Akron MSA; and Holmes has one of the highest Amish populations in the U.S., and tourism has been rapidly growing.

2) These counties also suggest that outliers may be part an artifact of measures for two reasons. First, Holmes, with its high Amish population, is not wellcaptured with conventional measures of formal sector employment, income, and education. Formal sector employment is less likely to be a good indicator of livelihood chances, and income and employment may be under-reported and/or segments of the population missed. This likely produces instability in reported federal statistics over time. Second, faster-reduced poverty counties had considerably lower median family income and higher poverty in 1990.

\footnotetext{
${ }^{8}$ As shown in Figure 1, in Anderson, Goe, and Weng’s analysis, Meigs and Morgan counties were initially outliers but the model fit improved when the spatial lag term was added to the specification.
} 
(For example, the mean family poverty rates were 13.6 percent in faster reduced counties compared to 11.2 percent in slower reduced counties in 1990 , and income median family income average was about $\$ 1000$ lower in 1990). These counties had poorer conditions in 1990 to begin with, which makes propensity for reduction greater.

\subsection{Interviews with Officials in Outlier Counties}

Thus far, we have identified two sets of factors that potentially distinguish outliers: local institutional arrangements related to the state and whether the county is located in a growing/declining region, including experiencing increased urban influence. To assess these two factors further, we draw from interviews with county officials in each outlier county. Ohio counties are particularly important for studying the working poor as Temporary Assistance to Needy Families (welfare) is devolved directly to counties. Interviews using a short, structured questionnaire were conducted in summer 2006. We selected the officials from a roster at the Ohio County Commissioners association and aimed for three officials from each county, a county commissioner, director of social services, and director of economic development in each of the 15 outlier counties. All counties have at least one of these respondents, and eight have two or more. We compiled their responses regarding regional growth/decline and the role of county government in improving local conditions. Officials' comments parallel differences we outlined above in terms regional/urban influences and government.

In brief, officials' comments support the idea that location in a more rapidly urbanizing region as well as state capacity issues are related to reduced rates of working poor. That is, in counties where the working poor population declined the most, officials were more likely to report the local economy as good or fair. They report more rapid population growth; problems with affordable housing; and also the need for better services such as improved schools, health care, and infrastructure (such as Internet and highway access) to service this growing population. These counties were less likely to report any funding shortages for county economic development efforts. By contrast, officials from increased poor counties are more likely to characterize the local economy as fair or poor and report slow or no growth. All note the limited number of major employers as a problem. They are more likely to report funding shortages for county economic development activities and for a wider range of social services than outlier counties where the working poor decreased.

However, despite some differences, it is important to note that there are also many similarities between the two groups of outlier counties. Officials across both sets of counties delineate standard rural-related barriers to economic development-distance from jobs, quality of jobs, and quality of workforce-as problems. All see declining state revenues and unfunded mandates as major problems in improving local well-being. Finally, they all tend to report increases in county administrative workload in responding to their population's needs. 
In summary, the analysis of Ohio adds a set of factors that reflect the context of the more urbanized, northern manufacturing belt as well as the capacity of the local state. The influence of past regional location within Ohio is seen in greater growth of the working poor in counties closer to de-industrialized metro areas and in Appalachia, while declines in the working poor are associated more with urban influence. The capacity of the local government to improve quality of life also varies somewhat across counties. In areas where the working poor have grown, government capacity in terms of enhancing local economic development and providing public services is lower. Our analysis indicates that both regional/urban influences and state capacity need to be scrutinized in understanding outlier counties in the North Central region. The diversity of reasons underlying Ohio cases also underscores the fact that aggregate analysis, useful as it is, just cannot capture it all, even with the best classification system. ${ }^{9}$

\section{SOUTH DAKOTA OUTLIERS AMONG AMERICAN INDIAN COUNTIES}

In South Dakota, two American Indian reservation outlier counties, Dewey and Todd, were selected for analysis because they differed in changes in their working poverty rates between 1990 and 2000. They are also similar to one another in that both include reservations and thus have high percentages of American Indians-72 percent for Dewey County and 82.6 percent for Todd County (U.S. Census 2000). Table 4 provides the change in percent of working poor from 1990 to 2000 for the two counties. Dewey County's working poverty decreased between 1990 and 2000, while Todd County's working poverty increased slightly.

The first factor that may contribute to the working poverty differences in Dewey and Todd Counties is change in the nature of government work between 1990 and 2000 (Table 5). While Anderson, Goe and Weng's model includes government employment, not captured in their model is the fact that the nature of government employment has changed due to changes in the Bureau of Indian Affairs and related federal efforts to push responsibility for administering programs to local units of government (National Congress of American Indians 1999). Both counties increased the percentage of government employees, which includes tribal jobs, between 1990 and 2000 (Labor Market Information Center 2006). These jobs are generally lower paying and have fewer benefits than the Bureau of Indian Affairs (BIA) jobs they replaced. The proportion of government employed workers increased much more in Todd County than Dewey County. However, in addition to the government jobs, Dewey County increased the number of educational/ health sector jobs while they decreased in Todd County. Educational and health jobs are relatively high paying jobs with benefits. Both Todd and Dewey counties have growing tribal colleges; the tribal college in Dewey County is newer and is thus expanding more. Beyond the direct employment at the college, the increase in worker access to tribal college training programs may have helped reduce Dewey County's rate of working poor.

\footnotetext{
${ }^{9}$ We thank Peter Schaeffer for this insight.
} 
TABLE 4

\begin{tabular}{|c|c|c|}
\hline Characteristic & Dewey & Todd \\
\hline Working Poor 1990 & $28.54 \%$ & $32.09 \%$ \\
\hline Working Poor 2000 & $20.56 \%$ & $32.20 \%$ \\
\hline Change 1990-2000 & $-7.98 \%$ & $+.11 \%$ \\
\hline \multicolumn{3}{|c|}{ Data from 2000 U.S. Census. } \\
\hline
\end{tabular}

TABLE 5

Change in Employment, Selected Sectors, 1990 to 2000, Dewey and Todd Counties

\begin{tabular}{lcc}
\hline \multicolumn{1}{c}{ Sector } & Dewey & Todd \\
\hline Government & $115 \%$ (650 more jobs) & $174.1 \%(1280$ more jobs $)$ \\
Education/health services & $58.3 \%$ (35 more jobs) & $-52.4 \%(165$ fewer jobs $)$ \\
\hline Data from 2000 U.S. Census. & & \\
\hline
\end{tabular}

Additional factors that may contribute to changes in the rate of working poor differences are commuting and housing. Dewey and Todd counties have tribal colleges that provide employment opportunities for American Indian residents. However, many faculty at tribal colleges are non-Indian. Dewey County residents employed in education increased by 58 percent, while Todd County's figures decreased slightly (Labor Market Information Center 2006). Commuting of employees may explain some of this difference. Many college and high school faculty and staff commute to Todd County from neighboring counties in South Dakota and Nebraska; this may be related to the fact that the entire area of Todd County lies within a reservation, which may make it less welcoming to other ethnic groups. On the other hand, Dewey County's land area is not 100 percent reservation, and educators may be more likely to reside within the county boundaries. Dewey County is located near Lake Oahe (a reservoir on the Missouri River). The lake makes it difficult for commuters east of the river to commute into Dewey County to work because of the added distance to travel. Also, Todd County is located adjacent to counties with higher median home values (Table 6), so proximity to a higher amenity county may drain people with higher paying jobs out of the county.

In summary, Dewey County may have decreased its rate of working poor because of the sector employment increases in education and health, and because neighboring counties do not draw its higher paid people away. Todd County increased in working poverty slightly. The high commute rate into this county may mean that fewer locals are working at the tribal college, high schools, and elsewhere in Todd County. The nonlocal employment translates into lower multiplier effects, reduced growth of the service sector, and perhaps less volunteer leadership capacity in the community. 
TABLE 6

\begin{tabular}{|c|c|c|}
\hline \multicolumn{3}{|c|}{ Commuting and Housing in Dewey and Todd Counties } \\
\hline & $\begin{array}{c}\text { Dewey County } \\
\text { (2000 Population 5,972) }\end{array}$ & $\begin{array}{c}\text { Todd County } \\
\text { (2000 Population 9,050) }\end{array}$ \\
\hline Commuting In, 1990 & $6.1 \%$ & $7.4 \%$ \\
\hline Commuting In, 2000 & $7.2 \%$ & $10.8 \%$ \\
\hline $\begin{array}{l}\text { Commuters' Home } \\
\text { Counties }\end{array}$ & Corson, Ziebach & Tripp, Cherry (NE) \\
\hline Median Home Value & $\$ 36,000$ & $\$ 27,500$ \\
\hline $\begin{array}{l}\text { Median Home Value for } \\
\text { Commuting Counties }\end{array}$ & $\$ 29,950$ & $\$ 56,800$ \\
\hline $\begin{array}{l}\text { Distance to Larger Town } \\
\text { ( } 2000 \text { population in } \\
\text { parentheses) }\end{array}$ & $\begin{array}{l}\text { Gettysburg - } 71 \text { miles }(1,352) \\
\text { Fort Pierre - } 90 \text { miles }(1,991)\end{array}$ & $\begin{array}{l}\text { Winner }-43 \text { miles }(3,137) \\
\text { Valentine }-31 \text { miles }(2,820)\end{array}$ \\
\hline
\end{tabular}

\section{SUMMARY AND CONCLUSIONS}

We have shown that much richer conclusions about the reasons for exceptional performance of regional economies can be drawn by utilizing other kinds of data to supplement regression analysis of federal census data. The Michigan case provides evidence that community-wide attitudes may play a role in determining different outcomes, even within a fairly limited geographic area like the Upper Peninsula. The Missouri case shows that a confluence of unfortunate structural factors gave rise to an extremely poor outcome despite valiant efforts on the part of local officials to address the situation. The Ohio and South Dakota cases show that county performance is clearly linked to the performance of the economy immediately beyond the county's borders. The South Dakota cases also illustrated that natural barriers can play a role and that investments in higher order services may be associated with lower levels of working poor.

Multi-method approaches such as the examples reported above can help alleviate the shortcomings associated with relying strictly on econometric estimates for policy analysis. The results of multi-method studies could then be used to develop new indicators to be collected in routine federal data collection exercises, yielding better insights into the determinants of regional change. Others have suggested shortcomings in federal data sets (Krieger and Fee 1994). We provide here an example of how these shortcomings might be explored in relatively low-cost ways.

Econometric studies' dependence on conventional federal data sources limits the understanding of new determinants that are increasingly thought to drive economic development. For example, civic society, attitudes of residents, and general overall "culture" of economic development of both residents and local government officials cannot generally be examined through federal data sources (Reese and Rosenfeld 2002). 
We have shown that the highly aggregated data conventionally used in econometric studies does not fully capture the depth and detail needed to understand outliers. For example, the case studies show the need to consider disaggregated employment sectors such as higher order services as well as to distinguish differences within the public sector between local, state, and federal governments. Further, although most econometric studies include population and location-related variables, their high level of aggregation makes it difficult to capture regionally-specific migration patterns and special populations such as the Amish and Native American populations.

\section{REFERENCES}

Anderson, C., R. Goe, and C. Weng, 2007. "A Multi-Method Research Strategy for Understanding Change in the Rate of Working Poor in the North Central Region of the United States,” The Review of Regional Studies 37(3), 361-391.

Anselin, L., 1988. Spatial Econometrics: Methods and Models. Kluwer Academic Publishers: Dordrecht.

City of New Madrid, 2006. http://www.new-madrid.mo.us, last accessed 10/31/2006.

Community Economic Toolbox, 2006. Department of Geography, The Pennsylvania State University, www.economictoolbox.geog.psu.edu, last accessed 10/31/2006.

Krieger, N. and E. Fee, 1994. "Social Class: The Missing Link in U.S. Health Data," International Journal of Health Services 26, 391-418.

Labor Market Information Center, 2006. "Nonfarm Wage and Salaried Workers Area Data,” Accessed July 31, 2006 at www.state.sd.us/applications/ld541micinfo/NON FARM/NFLISTPUBC.ASP.

LeSage, J., 1999. "Spatial Econometrics," in S. Loveridge (ed.) The Web Book of Regional Science, www.rri.wvu.edu/regscweb.htm. Regional Research Institute, West Virginia University: Morgantown, WV.

Lobao, L., 2004. "Continuity and Change in Place Stratification: Spatial Inequality and Middle-Range Territorial Units,” Rural Sociology 69, 1-30.

Loveridge, S., 1996. "On the Continuing Popularity of Industrial Recruitment," Economic Development Quarterly 10(2), 151-158.

Loveridge, S., J. Bokemeier, and P. Kakela, 2007. "Jobs Now, Later, or...Never? An Exploration of Resistance to Economic Change in Communities," Community Development: Journal of the Community Development Society 38(2), 16-32.

McGranahan, D.A., 1999. "Natural Amenities Drive Rural Population Change,” Agricultural Economic Report No. 781, U.S. Department of Agriculture. U.S. Government Printing Office: Washington D.C.

McKean, J.R., D.M. Johnson, R.L. Johnson, and R.G. Taylor, 2005. “Can Superior Natural Amenities Create High-Quality Employment Opportunities? The Case of Nonconsumptive River Recreation in Central Idaho," Society and Natural Resources 18, 749-758.

Missouri Economic Research and Information Center, 206. Missouri Industry Employment Information www.missourieconomy.org/industry/emp_wage/index.stm, last accessed 10/31/2006. 
Molotch, H., 1976. "The City as a Growth Machine: Toward a Political Economy of Place,” American Journal of Sociology 82(2), 309-332.

Missouri Department of Economic Development, 2006. “Governor Blunt Announces New Madrid County will Receive Enhanced Enterprise Zone Status” News release. Accessed at http://ded.mo.gov/cgi-bin/dispress.pl?txtpressid=1734.

National Congress of American Indians, 1999. "A Comprehensive Review of NCAI's Efforts to Address the Impacts of Welfare Reform in Indian Country," presented to the Senate Committee on Indian Affairs Briefing on Welfare Reform in Indian Country. Accessed at http://www.ncai.org/ncai/advocacy/hr/docs/WRimpacts.htm.

Rappaport, J., 2007. "Moving to Nice Weather,” Regional Science and Urban Economics 37(3), 383-432.

Reeder, R. and D. Brown, 2005. "Recreation, Tourism, and Rural Well-Being,” ERR-7, USDA, Economic Research Service, www.ers.usda.gov/publications/err7.

Reese, L. and R. Rosenfeld, 2002. The Civic Culture of Local Economic Development. Sage: Thousand Oaks, CA.

Southeast Missourian, 2004. "New Madrid Firm Bounces back from Telecom Bust," Southeast Missourian, July 12.

Troldahl, V.C. and Carter, R.C., 1964. "Random Selection of Respondents within Household Phone Surveys,” Journal of Marketing Research 1, 71-76.

United States Census Bureau, 2006. Retrieved July 26, 2006, www.census.gov.

Zekeri, A., 2000. "Is the City Really a Growth Machine? A Case Study of Forestville, Alabama," in P. Schaeffer and S. Loveridge (eds.), Small Town and Rural Economic Development: A Case Studies Approach. Praeger: Westport CT. 